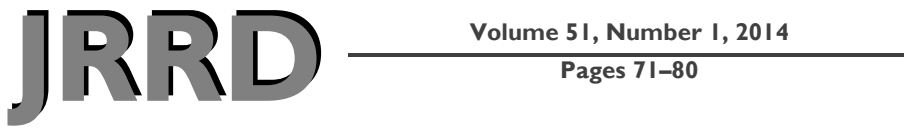

\section{Chronic visual dysfunction after blast-induced mild traumatic brain injury}

\author{
M. Teresa Magone, MD; ${ }^{*}$ Ellen Kwon, OD; Soo Y. Shin, MD \\ Department of Surgery/Eye Clinic, Department of Veterans Affairs Medical Center, Washington, DC
}

\begin{abstract}
The purpose of this study was to investigate the long-term visual dysfunction in patients after blast-induced mild traumatic brain injury (mbTBI) using a retrospective case series of 31 patients with mbTBI ( $>12$ mo prior) without eye injuries. Time since mbTBI was $50.5+/-19.8 \mathrm{mo}$. Age at the time of injury was $30.0+/-8.3$ yr. Mean corrected visual acuity was $20 / 20$. Of the patients, $71 \%(n=22)$ experienced loss of consciousness; $68 \%(n=15)$ of patients in this subgroup were dismounted during the blast injury. Overall, 68\% $(n=21)$ of patients had visual complaints. The most common complaints were photophobia (55\%) and difficulty with reading (32\%). Of all patients, 25\% were diagnosed with convergence insufficiency and $23 \%$ had accommodative insufficiency. Patients with more than one mbTBI had a higher rate of visual complaints (87.5\%). Asymptomatic patients had a significantly longer time (62.5 +/- $6.2 \mathrm{mo})$ since the mbTBI than symptomatic patients $(42.0+/-16.4 \mathrm{mo}, p<0.004)$. Long-term visual dysfunction after mbTBI is common even years after injury despite excellent distance visual acuity and is more frequent if more than one incidence of mbTBI occurred. We recommend obtaining a careful medical history, evaluation of symptoms, and binocular vision assessment during routine eye examinations in this prepresbyopic patient population.
\end{abstract}

Key words: accommodative insufficiency, blast-induced traumatic brain injury, combat-related traumatic brain injury, convergence insufficiency, dismounted injury, eyes, loss of consciousness, mild traumatic brain injury, near vision deficit, photophobia, traumatic brain injury, visual dysfunction.

\section{INTRODUCTION}

The Department of Defense reports that over 250,000 servicemembers have been diagnosed with traumatic brain injury (TBI) since the conflicts in Afghanistan (2001-present) and Iraq (2003-2011) began [1]. Among deployed servicemembers, the average rate of newly diagnosed TBI has been 542 cases per month over the past 5 yr [2]. Mild TBI (mTBI) accounts for 77 percent of all cases over the past decade and is characterized by the following symptoms at the time of the trauma: loss of consciousness (LOC) for up to $30 \mathrm{~min}$ or an alteration in mental state and/or memory loss for less than $24 \mathrm{~h}[1]$. The natural history of mTBI has been described to be self-limited with a predictable course [3]. Most symptoms of mTBI resolve within 6 mo, and only a small subset of patients have persistent symptoms up to $1 \mathrm{yr}$ [3-5].

However, in a recent study of U.S. servicemembers with combat-related mTBI, mostly blast explosion induced, subjects were found to still meet the criteria for postconcussion disorder up to $5 \mathrm{yr}$ after their baseline

\footnotetext{
Abbreviations: LOC $=$ loss of consciousness, $\operatorname{mbTBI}=$ blastinduced mild traumatic brain injury, $\mathrm{mTBI}=$ mild traumatic brain injury, NPC = near point of convergence, $\mathrm{PRK}=$ photorefractive keratectomy, PTSD = posttraumatic stress disorder, TBI = traumatic brain injury, VA = Department of Veterans Affairs, VAMC = Department of Veterans Affairs Medical Center.

*Address all correspondence to M. Teresa Magone, MD; Department of Surgery/Eye Clinic, Department of Veterans Affairs Medical Center, 50 Irving St NW, Washington, DC 20422. Email: maria.magone@va.gov

http://dx.doi.org/10.1682/JRRD.2013.01.0008
} 
examination [6]. Blast-induced TBI, which is considered the signature injury for servicemembers deployed to Iraq and Afghanistan, is thought to be more complex than focal TBIs from sports concussions commonly observed in the civilian population [7]. The mechanisms of the primary injury from exposure to the shockwave are not well understood, but the ensuing shear forces seem to play an important role in the mechanism of blast-induced cellular and axonal injury, which is typically anatomically more diffusely and evenly distributed than a focal injury [7-11].

Previously, Wilk et al. reported that among servicemembers with mTBI who reported LOC, blast mechanism of injury was significantly associated with symptoms such as memory problems, dizziness, sensitivity to light, and headaches 3 to 6 mo postdeployment compared with a nonblast mechanism [12]. Lew et al. noted a high percentage of self-reported vision problems, photophobia, and oculomotor dysfunction during vision screening examinations of patients with predominantly mTBI [13]. Cockerham et al. described the early effect of blast-induced TBI without direct eye injury on the visual system [14]. Findings included visual field defects, decrease in contrast sensitivity, and hidden ocular injuries from blunt trauma despite good visual acuity. Stelmack et al. and Brahm et al. both reported visual problems and high rates of accommodative and convergence insufficiency in retrospective studies of patients with blastinduced TBI in subacute settings [15-16]. Brahm et al.'s study included patients with mTBI of blast and non blast mechanisms [16], whereas Stelmack et al. did not report the degree of TBI [15]. A more recent study found significant visual dysfunction in servicemembers 45 to $60 \mathrm{~d}$ after blast-induced mTBI (mbTBI) compared with deployed controls without TBI [17]. However, none of these studies present long-term results in patients without direct eye injuries. Recognizing chronic visual symptoms and dysfunction in this young patient population is crucial for successful intervention and reintegration into the civilian work force and society. In the present study, we researched whether visual symptoms and ocular dysfunction are present more than 12 mo after mbTBI in veterans without eye injuries.

\section{METHODS}

All patients with the diagnosis of mbTBI longer than 12 mo prior to the eye examination and no history of eye injury before, during, or after the mbTBI who presented to the Washington DC Department of Veterans Affairs (VA) Medical Center (VAMC) eye clinic between January 1, 2009, and December 31, 2011, were included in this retrospective study, and their electronic medical records were reviewed. Exclusion criteria included any other category than mbTBI and any injury after deployment. Confirmation of the diagnosis and date of mbTBI was obtained from the second TBI evaluation examination performed by the polytrauma service and documented in the medical record. Date of injury, mechanism of injury (mounted vs dismounted, LOC), age at injury, time since injury, medications, visual symptoms, visual acuity, employment status, and documented eye examination results were reviewed and analyzed. In two patients, only the month and year of the injury were documented in the medical record. Therefore, the 15th day of the corresponding month was entered for calculation of the time since the injury.

Cover testing was performed in primary gaze at distance and near. Distance visual acuity was measured using the projected Snellen eye chart. Accommodative insufficiency was diagnosed when the lower limit of the expected value for the patient's age was abnormal according to Hofstetter's formula [18]. Convergence insufficiency was diagnosed when there was exophoria greater at near compared with distance, an abnormal near point of convergence (NPC), and positive fusional vergence. NPC measures the ability to maintain binocularly with increased accommodative and vergence demand. NPC was measured with the red lens method. A red lens was placed in front of patient's right eye and the muscle light was moved close to the patient until the break (two lights) was reported or a break in fusion was observed by the examiner. A remote NPC with a break of greater than $8 \mathrm{~cm}$ and recovery greater than $12 \mathrm{~cm}$ was considered abnormal [18].

\section{STATISTICAL ANALYSIS}

Mean and standard deviation values were calculated using SAS version 9.3 (SAS Institute Inc; Cary, North Carolina) and Graphpad Prism software version 4.0 (GraphPad Software Inc; La Jolla, California). Mean visual acuity of the right and left eye of each patient was used to calculate the total mean visual acuity. The unpaired, two-tailed $t$-test was used to compare the time 
since injury between groups. Subgroup analysis was performed using the Fisher test for patients without symptoms and not taking any medications and to evaluate LOC and a dismounted mechanism of injury.

\section{RESULTS}

From January 2009 to December 2011, a total of 192 patients with the diagnosis of TBI presented to the Washington DC VAMC eye clinic for examinations. Of these patients, 31 experienced mbTBI without eye injury during the conflicts in Iraq or Afghanistan and were included in the study. The majority of patients were male (94\%) and the mean age at the time of injury was $30.5 \pm 8.3 \mathrm{yr}$. Only 54 percent of the patients actively reported a history of TBI in their past medical history during the eye examination. However, documentation of mbTBI in the secondary TBI assessments performed by the polytrauma service at our VAMC were available in the electronic medical record. Of these patients, 18 (58\%) were dismounted (on the ground) during the injury, whereas 13 (42\%) were inside a military vehicle during the injury. Three patients had refractive surgery prior to their deployment.

The mean time interval between the mbTBI and documented eye examination was $50.5 \pm 19.8$ mo (range: 16$91 \mathrm{mo}$ ). All patients had a mean best-corrected visual acuity of 20/20 (logMar 0). Of the 31 patients, 27 (87\%) were employed in full-time positions, whereas 4 (13\%) were unemployed.

Two patients above $40 \mathrm{yr}$ of age were diagnosed with physiologic presbyopia. To avoid bias in the analysis, their near vision complaints were excluded from the data analysis.

There was no documented evidence of anterior segment inflammation or any other abnormalities on slit lamp examination. Dilated examination revealed an old atrophic hole in the retinal periphery of one patient.

\section{Visual Symptoms}

Visual complaints were found in 68 percent $(n=21)$ of patients (Table 1). They were as follows: 55 percent reported problems with photophobia, 32 percent with reading and near work, 19 percent with floaters, 13 percent with diplopia, and 3 percent with pain above the eyes. Ten patients (32\%) had no visual complaints. Patients with more than one mbTBI $(n=8)$ had a higher rate of visual problems (87.5\%) than patients with only one reported mbTBI $(61 \%)$ but the difference was not statistically significant $(p<0.22)$. Asymptomatic patients had significantly longer time $(62.5 \pm 6.2 \mathrm{mo})$ since the mbTBI than symptomatic patients $(41.8 \pm 16.4$ mo, $p<$ 0.004 , unpaired $t$-test) (Figure). No patients reported visual symptoms $\geq 70$ mo after mbTBI.

\section{Photophobia}

The most frequent complaint was light sensitivity, which was present in 55 percent of patients and ranged from mild to moderate as described by the patients. For alleviation of their symptoms, all patients with photophobia received "wraparound" framed glasses with polarized lenses tinted with light transmission according to the patient's preference for optimal comfort.

Three patients had undergone refractive surgery before deployment (two LASIK and one photorefractive keratectomy [PRK]). One of the LASIK patients was not symptomatic. His mbTBI occurred 61 mo prior to the eye examination and he was inside a vehicle during the explosion, possibly altering the impact of the blast. The other two patients complained of photophobia. Both were dismounted during the blast and were on no medications at the time of the eye examination. The time since injury was 18 mo for the PRK patient and 42 mo for the LASIK patient.

\section{Near Vision Dysfunction}

On eye examination, eight (25\%) patients were diagnosed with convergence insufficiency and seven (23\%) had accommodative insufficiency. The average NPC in patients diagnosed with convergence insufficiency was $29.2 \pm 24.0 \mathrm{~cm}$ (normal range: $2.5 \pm 2.5 \mathrm{~cm}$ ). Of the patients who were unemployed $(n=4), 75$ percent were diagnosed with accommodative insufficiency and/or convergence insufficiency, compared with only 33 percent of employed patients $(n=27)$. All patients with accommodative insufficiency were given reading and computer glasses.

\section{Loss of Consciousness}

Of the patients, 22 (71\%) experienced LOC and 9 (29\%) had an alteration of mental state without LOC (Table 1). Patients who experienced LOC did not experience more visual symptoms (64\%) than patients who only had an altered mental status (78\%, $p<0.67)$. Subgroup analysis showed that patients who were dismounted 
JRRD, Volume 51, Number 1, 2014

Table 1.

Visual symptoms after blast-induced mild traumatic brain injury (mbTBI).

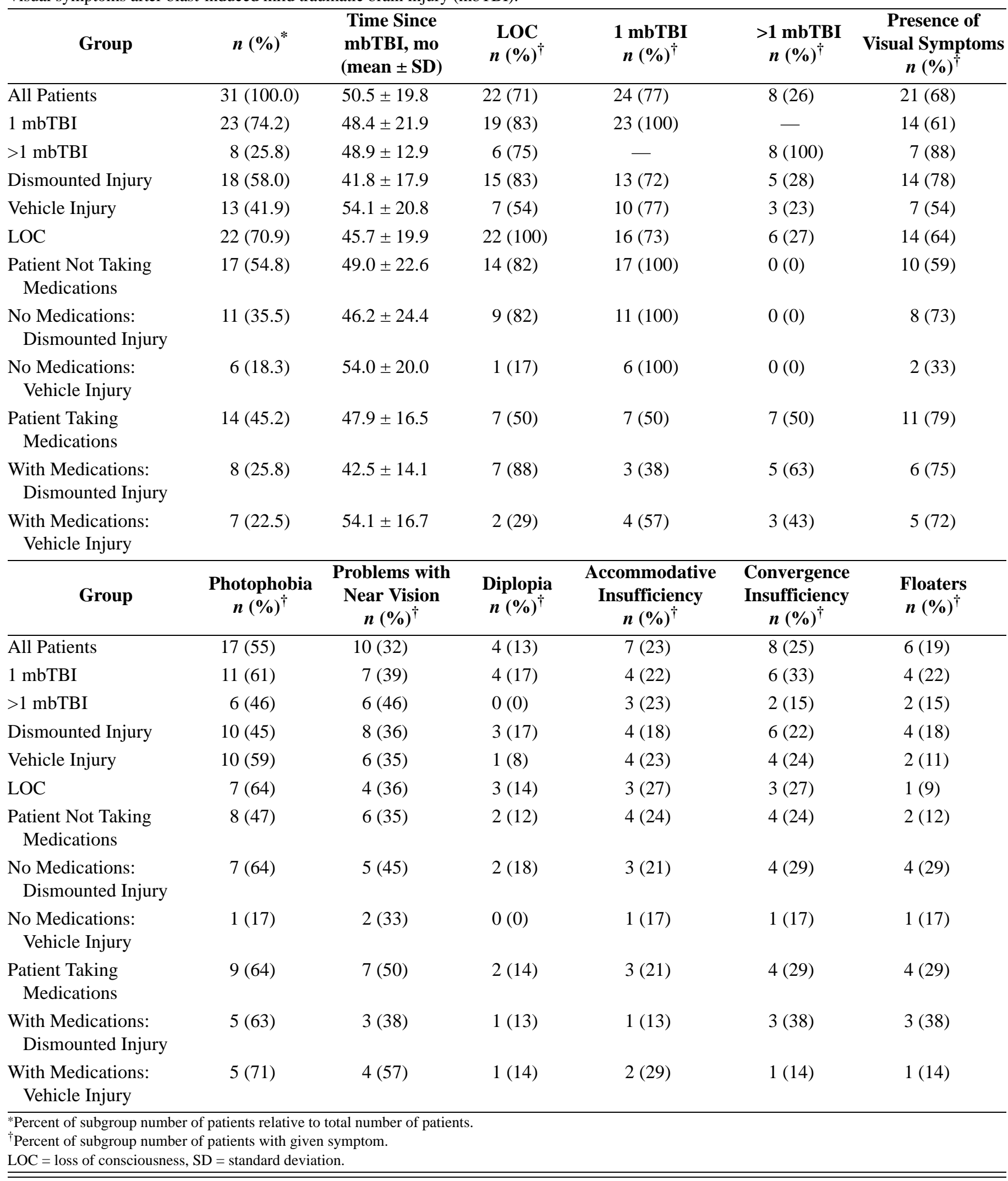




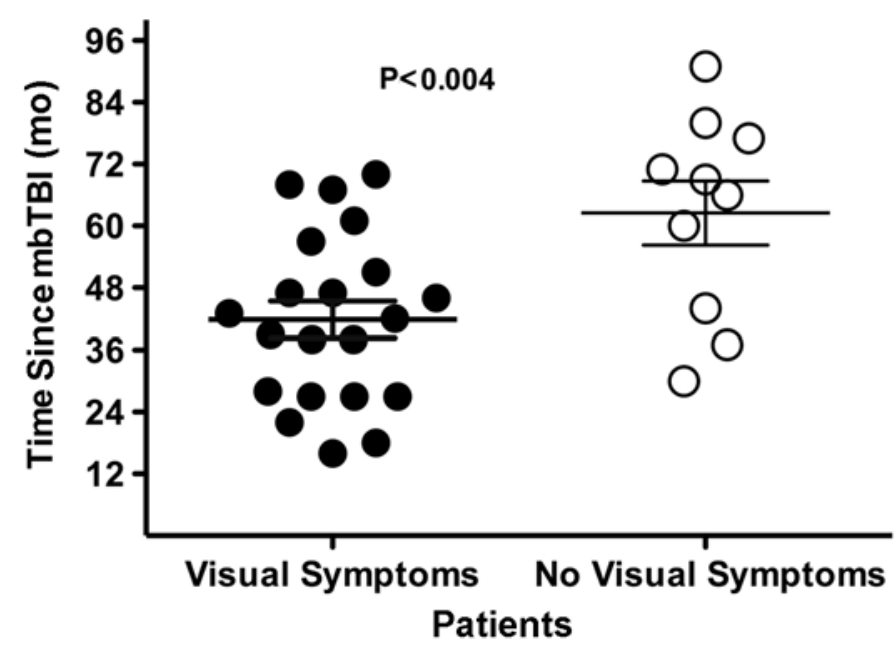

Figure.

Patients with and without visual symptoms and time since blast-induced mild traumatic brain injury (mbTBI).

during the exposure to the blast had more symptoms (78\%) than patients who were inside a vehicle (54\%) during the explosion, but the difference was not statistically significant $(p<0.24)$. In addition, patients who were involved in a dismounted mechanism of blast injury $(n=$ 18) had the highest percentage $(82 \%, n=15)$ of LOC of all subgroups (Table 1).

\section{Medication Use}

Table 2 lists the medications used by 14 of the patients in the current study. Patients who did not take any medications $(n=17)$ had fewer visual symptoms $(59 \%)$ than patients on medications ( $n=14,79 \%$ ), but the difference was not found to be statistically significant ( $p<$ 0.45 , Fisher test). A significantly higher rate of patients who experienced LOC with a dismounted mechanism were taking medications (88\%) compared with patients with LOC from an injury while inside a vehicle $(29 \%, p<$ 0.04). Similarly, a higher percentage of patients with more than one episode of mbTBI was on medications (88\%) compared with patients who experienced only one mbTBI $(30 \%, p<0.01)$.

\section{DISCUSSION}

It is estimated that nearly half of all injured servicemembers in Operation Enduring Freedom and Operation
Iraqi Freedom were injured by explosive devices and experienced neurotrauma [7]. Blast-induced TBI is being widely studied, but its long-term effect on the visual system remains unknown. Observations suggest that the mechanism by which explosive blast injuries damage the central nervous system may be more diffuse and evenly distributed throughout the brain than initially assumed [8-9]. Many factors influence the degree of a primary blast injury, including the distance to the detonation and whether the explosion occurred within an enclosed structure, because the latter can reflect the shockwave and increase both exposure time and tissue damage [19-21]. The human eye, with its dual cameral system and delicate structures, may be vulnerable to blast-wave and shearforce injury, even when there is no obvious direct trauma to the eye. Previously, Cockerham et al. reported occult ocular damage in patients after blast exposure [14]. Brahm et al. published a retrospective study describing significant visual dysfunction of a large number of servicemembers in acute and subacute phases of rehabilitation [16]. These authors also found a high rate of visual impairment and near-work related deficiencies in their patient population despite relatively normal visual acuity and normal visual fields. Later studies report that veterans with blast-induced TBI with auditory deficits are likely to also have visual disturbances and vice versa [22-23]. Since the auditory and visual organs have fluid levels, they are more likely to be affected by an explosive blast wave.

We found evidence that the visual dysfunction and symptoms in these patients persist for a much longer time period than previously reported. Typically, a normal distance visual acuity presumes a healthy visual system in young patients. Our data highlights abnormalities of the visual system after mbTBI in a young patient population with excellent vision, despite the fact that our study has a retrospective design and a small sample size. Limitations of the study are that no computed tomography scan was obtained at the time of original injury, which may be difficult to achieve for mTBI in the war zone. Only patients who reported reading problems or were in the presbyopic age range were routinely evaluated for near vision deficits. Therefore, no data are available on the incidence of accommodative and convergence insufficiency in asymptomatic patients. Also, since patients came in for routine examinations, no visual field testing was performed. However, all our patients were exposed to one or more blast explosions in the war zone and at that time developed symptoms that 
JRRD, Volume 51, Number 1, 2014

Table 2.

List of medications used by 14 of 31 patients and reported visual symptoms.

\begin{tabular}{|c|c|c|c|c|c|c|c|c|}
\hline Medication & $\begin{array}{c}\text { Total } \\
\text { Patients } \\
\text { (n) }\end{array}$ & Indication & $\begin{array}{c}\text { Photophobia } \\
\text { (n) }\end{array}$ & $\begin{array}{l}\text { Near Vision } \\
\text { Problems } \\
\text { (n) }\end{array}$ & $\begin{array}{l}\text { Accommodative } \\
\text { Insufficiency } \\
\text { (n) }\end{array}$ & $\begin{array}{l}\text { Convergence } \\
\text { Insufficiency } \\
\text { (n) }\end{array}$ & $\begin{array}{c}\text { Time } \\
\text { Since } \\
\text { TBI (mo) }\end{array}$ & $\begin{array}{c}>1 \\
\text { mbTBI } \\
(n)\end{array}$ \\
\hline Sertaline & 4 & Depression & 3 & 2 & 0 & 1 & 36.2 & 2 \\
\hline Nortryptiline & 2 & Depression & 1 & 2 & 1 & 0 & 32.5 & 1 \\
\hline $\begin{array}{l}\text { Hydrocodone/ } \\
\text { Acetaminophen }\end{array}$ & 1 & Pain & 0 & 1 & 0 & 1 & 27 & 1 \\
\hline Tramadol & 1 & Pain & 1 & 0 & 0 & 0 & 46 & 0 \\
\hline Ibuprofen & 1 & Pain & 1 & 1 & 1 & 1 & 38 & 1 \\
\hline Naproxen & 6 & Pain & 5 & 1 & 0 & 1 & 42.5 & 1 \\
\hline Meloxicam & 1 & Anti-Inflammatory & 0 & 0 & 0 & 0 & 44 & 1 \\
\hline Methocarbamol & 1 & Muscle Relaxation & 1 & 0 & 0 & 1 & 43 & 0 \\
\hline Cyclobenzaprine & 1 & Muscle Relaxation & 0 & 0 & 0 & 0 & 44 & 1 \\
\hline Amlodipine & 1 & Hypertension & 0 & 0 & 0 & 0 & 77 & 1 \\
\hline Prazosin & 2 & Hypertension & 0 & 0 & 0 & 0 & 46 & 2 \\
\hline Meclizine & 1 & Motion Sickness & 1 & 0 & 0 & 0 & 47 & 1 \\
\hline Quetiapine & 1 & PTSD & 2 & 0 & 0 & 1 & 68 & 1 \\
\hline Vardenafil & 2 & Erectile Dysfunction & 1 & 1 & 0 & 2 & 43 & 0 \\
\hline
\end{tabular}

were consistent with mTBI. None of our patients had a history of any other trauma before, during, or after their deployments.

Our study also highlights that ocular motor abnormalities, which are often present in the early stages after TBI, may still affect patients years after the blast injury despite excellent vision. The rate of convergence insufficiency has been reported to be about 3 to 5 percent in the general population and 9 percent in civilian patients after TBI, which is three- to fivefold lower than the rate of 25 percent in our study population [24-25].

In the current study, sensitivity to light was the most commonly reported ocular symptom. Although photophobia in the absence of ocular inflammation is a common symptom described after TBI, the exact mechanism remains unknown [14-16,26-28]. Bohnen et al. showed that tolerance to light and sound decreased in patients 6 mo after mTBI compared with control subjects and suggested that the cause was a cortical and subcortical lack of inhibitory control [27]. Nonuniform cortical excitability has also been described in other brain disorders associated with photophobia, such as migraines and epilepsy [29-32] A cortical hyperresponsitivity could interfere with visual perception, leading to photophobia. The trigeminal nerve and its nuclei are the primary mediators of pain sensation in the eye and the ocular structures are densely innervated with trigeminal fibers [28]. During the explosion, an overpressure wave passes through the organs, including the eye, and the cytostructures may be affected [19]. A possible trigeminal trigger in these patients could be caused by light entering the eye. Further research is needed to elucidate the complex pathogenesis of this common complaint after TBI.

Medication intake was previously discussed as a contributing factor for visual symptoms; for example, it is known that the medications used for depression, pain, and posttraumatic stress syndrome can have side effects on the visual system [17,33]. In the present study, patients who were on medications had higher percentages of visual symptoms than nonmedicated patients, but the difference between groups was not statistically significant $(p<0.2)$ (Table 1). In addition, 59 percent of the patients in the current study who were not on medications still had visual symptoms, and 24 percent of these patients had accommodative insufficiency and/or convergence insufficiency. This indicates that while side effects from certain medications can aggravate some of the visual symptoms typically associated with mbTBI, other causes for the visual dysfunction need to be considered in this patient population.

In our study, patients with LOC had a higher percentage of photophobia and accommodation and convergence insufficiency than patients without LOC (Table 1). A dismounted mechanism of injury combined with LOC resulted in a significantly higher percentage of medication intake. Similarly, patients with more than one mbTBI had the highest rate of visual complaints, and a significantly higher percentage of those patients needed medication 
therapy compared with patients who experienced a single mbTBI (Table 1). However, in our retrospective study, the small number of patients who experienced more than one mbTBI limits statistical power.

In a recent study, Iraq combat veterans with more than one episode of mbTBI were found to have decreased cerebrocerebellar metabolic rates than controls without trauma [34]. This could explain the prolonged recovery in these patients. Our findings are consistent with previous reports of a cumulative effect after multiple TBIs resulting in increased postconcussive symptoms, although we highlight its effect on the visual system in this disorder [35-36].

An encouraging finding in the present study is the fact that visual symptoms were significantly less in patients who had more time since the combat-related mbTBI. In our study, no visual complaints were documented in patients who presented $\geq 70$ mo after the mbTBI.

Most of our patients were in their third decade of life and gainfully employed. It is likely that the majority of the 250,000 servicemembers diagnosed with TBI once separated from the military will enter the civilian workforce. The first $5 \mathrm{yr}$ after leaving the military are crucial for veterans to transition into a productive civilian life, and early recognition of visual dysfunction may improve successful reintegration into society. Occult visual problems may affect veterans' career choices negatively in addition to the frequent psychological and physical combat-related visible and invisible injuries they may have endured. The current literature discusses that the symptoms of mbTBI can overlap with posttraumatic stress disorder (PTSD) or that both may be concurrently present after serving in the war zone [21,37-38]. Patients with PTSD were reported to have sensitivity to light, blurred vision, dry eye syndrome, and vision-related side effects from medication therapy; however, no prospective studies have been published to evaluate visual health in this patient population [39-41]. Ocular motility problems such as accommodative and convergence insufficiency, which cause visual symptoms, are more likely to stem from organic brain disease and may be helpful in separating PTSD and ophthalmic problems in selected cases.

Employed patients may present to non-VA ophthalmologists and optometrists for eye examinations. We suggest asking these young patients whether they served in the military and have had a history of combat-related TBI, because only 54 percent of the patients in our study actively reported a past medical history of mbTBI during the eye examinations. Ideally, the NPC, extraocular motil- ity, monocular accommodative testing, and distance and near cover tests should be conducted in all patients with the diagnosis of mbTBI in order to evaluate for accommodative and convergence insufficiency. At a minimum, a simple screening test even the busiest provider should be able to perform during routine eye examinations is to assess the NPC. If the test is abnormal, then a more formal evaluation for binocular dysfunction is warranted. Recognition of the visual problems and treatment with computer and reading glasses, prisms, and tinted lenses for photophobia can be helpful in decreasing the patient's symptoms and improving the quality of life. In selected cases, vision therapy can also be offered, where available.

Our study reinforces that unrecognized visual problems may go unnoticed for years and are often not appropriately addressed. Based on recent literature reports, evidence is mounting that symptoms associated with combat-related postconcussion disorder in servicemembers can persist much longer than expected, and extended monitoring may be necessary in patients with chronic medical problems after TBI $[6,36,39]$ A coordinated multidisciplinary effort between specialties, including ophthalmology and optometry, is needed to monitor and recognize persistent problems in these young veterans.

\section{CONCLUSIONS}

In summary, chronic visual dysfunction and symptoms are frequently present in veterans even years after mbTBI despite excellent distance visual acuity. Symptoms appear to improve 5 to $6 \mathrm{yr}$ after injury and are more frequent if more than one episode of TBI was present or if the patient was dismounted at the time of injury. Assessment of symptoms and binocular vision testing in this prepresbyopic patient population should be routinely performed during eye examinations to recognize visual problems. Future studies are needed to evaluate in more detail the effect of blast injuries on the visual system of exposed patients.

\section{ACKNOWLEDGMENTS}

\section{Author Contributions:}

Study concept and design: M. T. Magone, S. Y. Shin.

Acquisition of data: M. T. Magone, E. Kwon.

Analysis and interpretation of data: M. T. Magone, S. Y. Shin.

Drafting of manuscript: M. T. Magone, E. Kwon. 
Critical revision of manuscript for important intellectual content:

M. T. Magone, S. Y. Shin.

Statistical analysis: M. T. Magone.

Administrative, technical, or material support: E. Kwon,

M. T. Magone.

Study supervision: M. T. Magone.

Financial Disclosures: The authors have declared that no competing interests exist.

Funding/Support: This material was unfunded at the time of manuscript preparation.

Additional Contributions: The authors would like to thank Dr. Richard Amdur and David Maron for their help with the statistical analysis of the data.

Institutional Review: The present study was approved by the institutional review board and research development office at our institution before initiation.

Participant Follow-Up: This is a retrospective review study, and the authors do not plan to inform participants of the publication of this study.

\section{REFERENCES}

1. Military Health System Office of Strategic Communications. DoD numbers for traumatic brain injury [Internet]. Washington (DC): Military Health System, U.S. Department of Defense; 2012 [updated 2012 Aug 20; cited 2013 Jul 15]. Available from: http://www.health.mil/Libraries/ TBI-Numbers-Current-Reports/dod-tbi-worldwide-20002012Q2-as-of-120820.pdf

2. Armed Forces Health Surveillance Center. Deploymentrelated conditions of special surveillance interest, U.S. Armed Forces, by month and service, January 2003September 2012. MSMR. 2012;19(10):19.

3. Iverson GL, Lange RT. The natural history of traumatic brain injury. In: Zollman FS, editor. Manual of traumatic brain injury. New York (NY): Demos Medical Publishing; 2011.

4. Zumstein MA, Moser M, Mottini M, Ott SR, SadowskiCron C, Radanov BP, Zimmermann H, Exadaktylos A. Long-term outcome in patients with mild traumatic brain injury: A prospective observational study. J Trauma. 2011; 71(1):120-27. [PMID:21045743]

http://dx.doi.org/10.1097/TA.0b013e3181f2d670

5. Schretlen DJ, Shapiro AM. A quantitative review of the effects of traumatic brain injury on cognitive functioning. Int Rev Psychiatry. 2003;15(4):341-49. [PMID:15276955] http://dx.doi.org/10.1080/09540260310001606728

6. Lange RT, Brickell TA, Ivins B, Vanderploeg RD, French LM. Variable, not always persistent, postconcussion symptoms after mild TBI in U.S. military service members: A five-year cross-sectional outcome study. J Neurotrauma. 2013;30(11):958-69. [PMID:23205671] http://dx.doi.org/10.1089/neu.2012.2743
7. French LM. Military traumatic brain injury: An examination of important differences. Ann N Y Acad Sci. 2010; 1208:38-45. [PMID:20955324]

http://dx.doi.org/10.1111/j.1749-6632.2010.05696.x

8. Nakagawa A, Manley GT, Gean AD, Ohtani K, Armonda R, Tsukamoto A, Yamamoto H, Takayama K, Tominaga T. Mechanisms of primary blast-induced traumatic brain injury: Insights from shock-wave research. J Neurotrauma. 2011;28(6):1101-19. [PMID:21332411]

http://dx.doi.org/10.1089/neu.2010.1442

9. Goldstein LE, Fisher AM, Tagge CA, Zhang XL, Velisek L, Sullivan JA, Upreti C, Kracht JM, Ericsson M, Wojnarowicz MW, Goletiani CJ, Maglakelidze GM, Casey N, Moncaster JA, Minaeva O, Moir RD, Nowinski CJ, Stern RA, Cantu RC, Geiling J, Blusztajn JK, Wolozin BL, Ikezu T, Stein TD, Budson AE, Kowall NW, Chargin D, Sharon A, Saman S, Hall GF, Moss WC, Cleveland RO, Tanzi RE, Stanton PK, McKee AC. Chronic traumatic encephalopathy in blast-exposed military veterans and a blast neurotrauma mouse model. Sci Transl Med. 2012;4(134): 134ra60. [PMID:22593173]

http://dx.doi.org/10.1126/scitranslmed.3003716

10. Magnuson J, Leonessa F, Ling GS. Neuropathology of explosive blast traumatic brain injury. Curr Neurol Neurosci Rep. 2012;12(5):570-79. [PMID:22836523] http://dx.doi.org/10.1007/s11910-012-0303-6

11. Desmoulin GT, Dionne JP. Blast-induced neurotrauma: Surrogate use, loading mechanisms, and cellular responses. J Trauma. 2009;67(5):1113-22. [PMID:19901677] http://dx.doi.org/10.1097/TA.0b013e3181bb8e84

12. Wilk JE, Thomas JL, McGurk DM, Riviere LA, Castro CA, Hoge CW. Mild traumatic brain injury (concussion) during combat: Lack of association of blast mechanism with persistent postconcussive symptoms. J Head Trauma Rehabil. 2010;25(1):9-14. [PMID:20051900] http://dx.doi.org/10.1097/HTR.0b013e3181bd090f

13. Lew HL, Poole JH, Vanderploeg RD, Goodrich GL, Dekelboum S, Guillory SB, Sigford B, Cifu DX. Program development and defining characteristics of returning military in a VA Polytrauma Network Site. J Rehabil Res Dev. 2007; 44(7):1027-34. [PMID:18075959] http://dx.doi.org/10.1682/JRRD.2007.05.0073

14. Cockerham GC, Goodrich GL, Weichel ED, Orcutt JC, Rizzo JF, Bower KS, Schuchard RA. Eye and visual function in traumatic brain injury. J Rehabil Res Dev. 2009; 46(6):811-18. [PMID:20104404] http://dx.doi.org/10.1682/JRRD.2008.08.0109

15. Stelmack JA, Frith T, Van Koevering D, Rinne S, Stelmack TR. Visual function in patients followed at a Veterans Affairs polytrauma network site: An electronic medical record review. Optometry. 2009;80(8):419-24. 


\section{[PMID:19635432]}

http://dx.doi.org/10.1016/j.optm.2009.02.011

16. Brahm KD, Wilgenburg HM, Kirby J, Ingalla S, Chang CY, Goodrich GL. Visual impairment and dysfunction in combat-injured servicemembers with traumatic brain injury. Optom Vis Sci. 2009;86(7):817-25. [PMID:19521270] http://dx.doi.org/10.1097/OPX.0b013e3181adff2d

17. Capó-Aponte JE, Urosevich TG, Temme LA, Tarbett AK, Sanghera NK. Visual dysfunctions and symptoms during the subacute stage of blast-induced mild traumatic brain injury. Mil Med. 2012;177(7):804-13. [PMID:22808887] http://dx.doi.org/10.7205/MILMED-D-12-00061

18. Scheiman M, Wick B. Clinical management of binocular vision. 3rd ed. Philadelphia (PA): Lippincott Williams \& Wilkins; 2008.

19. Wolf SJ, Bebarta VS, Bonnett CJ, Pons PT, Cantrill SV. Blast injuries. Lancet. 2009;374(9687):405-15.

[PMID:19631372] http://dx.doi.org/10.1016/S0140-6736(09)60257-9

20. DePalma RG, Burris DG, Champion HR, Hodgson MJ. Blast injuries. N Engl J Med. 2005;352(13):1335-42. [PMID:15800229] http://dx.doi.org/10.1056/NEJMra042083

21. Elder GA, Mitsis EM, Ahlers ST, Cristian A. Blast-induced mild traumatic brain injury. Psychiatr Clin North Am. 2010;33(4):757-81. [PMID:21093677] http://dx.doi.org/10.1016/j.psc.2010.08.001

22. Lew HL, Garvert DW, Pogoda TK, Hsu PT, Devine JM, White DK, Myers PJ, Goodrich GL. Auditory and visual impairments in patients with blast-related traumatic brain injury: Effect of dual sensory impairment on Functional Independence Measure. J Rehabil Res Dev. 2009;46(6): 819-26. [PMID:20104405] http://dx.doi.org/10.1682/JRRD.2008.09.0129

23. Lew HL, Weihing J, Myers PJ, Pogoda TK, Goodrich GL. Dual sensory impairment (DSI) in traumatic brain injury (TBI) - An emerging interdisciplinary challenge. NeuroRehabilitation. 2010;26(3):213-22. [PMID:20448311]

24. Kent PR, Steeve JH. Convergence insufficiency, incidence among military personnel and relief by orthoptic methods. Mil Surg. 1953;112(3):202-5. [PMID:13024855]

25. Alvarez TL, Kim EH, Vicci VR, Dhar SK, Biswal BB, Barrett AM. Concurrent vision dysfunctions in convergence insufficiency with traumatic brain injury. Optom Vis Sci. 2012;89(12):1740-51. [PMID:23190716] http://dx.doi.org/10.1097/OPX.0b013e3182772dce

26. Goodrich GL, Kirby J, Cockerham G, Ingalla SP, Lew HL. Visual function in patients of a polytrauma rehabilitation center: A descriptive study. J Rehabil Res Dev. 2007;44(7): 929-36. [PMID:18075950]

http://dx.doi.org/10.1682/JRRD.2007.01.0003
27. Bohnen N, Twijnstra A, Wijnen G, Jolles J. Tolerance for light and sound of patients with persistent post-concussional symptoms 6 months after mild head injury. J Neurol. 1991;238(8):443-46. [PMID:1779251] http://dx.doi.org/10.1007/BF00314651

28. Digre KB, Brennan KC. Shedding light on photophobia. J Neuroophthalmol. 2012;32(1):68-81. [PMID:22330853] http://dx.doi.org/10.1097/WNO.0b013e3182474548

29. Du T, Ciuffreda KJ, Kapoor N. Elevated dark adaptation thresholds in traumatic brain injury. Brain Inj. 2005;19(13): 1125-38. [PMID:16286326] http://dx.doi.org/10.1080/02699050500149817

30. Schrupp LE, Ciuffreda KJ, Kapoor N. Foveal versus eccentric retinal critical flicker frequency in mild traumatic brain injury. Optometry. 2009;80(11):642-50. [PMID:19861221] http://dx.doi.org/10.1016/j.optm.2009.04.097

31. Wilkins AJ, Bonanni P, Porciatti V, Guerrini R. Physiology of human photosensitivity. Epilepsia. 2004;45 Suppl 1:17-13. [PMID:14706038]

32. Coppola G, Pierelli F, Schoenen J. Is the cerebral cortex hyperexcitable or hyperresponsive in migraine? Cephalalgia. 2007;27(12):1427-39. [PMID:18034686] http://dx.doi.org/10.1111/j.1468-2982.2007.01500.x

33. Fraunfelder FT, Fraunfelder FW, Chambers WA. Clinical ocular toxicology: Drugs, chemicals, and herbs. Philadelphia (PA): Elsevier Saunders; 2008.

34. Peskind ER, Petrie EC, Cross DJ, Paqulayan K, McCraw K, Hoff D, Hart K, Yu CE, Raskind MA, Cook DG, Minoshima S. Cerebrocerebellar hypometabolism associated with repetitive blast exposure mild traumatic brain injury in 12 Iraq war Veterans with persistent post-concussive symptoms. Neuroimage. 2011;54 Suppl 1:S76-82.

[PMID:20385245]

http://dx.doi.org/10.1016/j.neuroimage.2010.04.008

35. Lew HL, Pogoda TK, Baker E, Stolzmann KL, Meterko M, Cifu DX, Amara J, Hendricks AM. Prevalence of dual sensory impairment and its association with traumatic brain injury and blast exposure in OEF/OIF veterans. J Head Trauma Rehabil. 2011;26(6):489-96. [PMID:21386715] http://dx.doi.org/10.1097/HTR.0b013e318204e54b

36. Lew HL, Poole JH, Guillory SB, Salerno RM, Leskin G, Sigford B. Persistent problems after traumatic brain injury: The need for long term follow-up and coordinated care. J Rehabil Res Dev. 2006;43(2):vii-X. [PMID:16847779]

37. Lew HL, Poole JH, Alvarez S, Moore W. Soldiers with occult traumatic brain injury. Am J Phys Med Rehabil. 2005;84(6):393-98. [PMID:15905652] http://dx.doi.org/10.1097/01.phm.0000163703.91647.a7

38. Hoge CW, McGurk D, Thomas JL, Cox AL, Engel CC, Castro CA. Mild traumatic brain injury in U.S. Soldiers returning from Iraq. N Engl J Med. 2008;358(5):453-63. 
JRRD, Volume 51, Number 1, 2014

[PMID:18234750]

http://dx.doi.org/10.1056/NEJMoa072972

39. Hill JJ 3rd, Mobo BH Jr, Cullen MR. Separating deployment-related traumatic brain injury and posttraumatic stress disorder in veterans: Preliminary findings from the Veterans Affairs traumatic brain injury screening program. Am J Phys Med Rehabil. 2009;88(8):605-14. [PMID:19620825] http://dx.doi.org/10.1097/PHM.0b013e3181ae0f83

40. Trachtman JN. Post-traumatic stress disorder and vision. Optometry. 2010;81(5):240-52. [PMID:20435270]

http://dx.doi.org/10.1016/j.optm.2009.07.017

41. Galor A, Feuer W, Lee DJ, Florez H, Faler AL, Zann KL, Perez VL. Depression, post-traumatic stress disorder, and dry eye syndrome: A study utilizing the national United States Veterans Affairs administrative database. Am J Ophthalmol. 2012;154(2):340-46, e2. [PMID:22541654] http://dx.doi.org/10.1016/j.ajo.2012.02.009
Submitted for publication January 16, 2013. Accepted in revised form July 11, 2013.

This article and any supplementary material should be cited as follows:

Magone MT, Kwon E, Shin SY. Chronic visual dysfunction after blast-induced mild traumatic brain injury. J Rehabil Res Dev. 2014;51(1):71-80.

http://dx.doi.org/10.1682/JRRD.2013.01.0008

ResearcherID/ORCID: M. Teresa Magone, MD: B-30732014

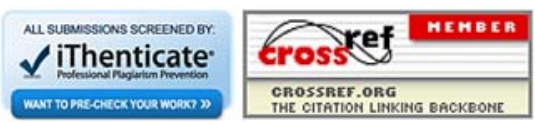

